\title{
Clinical features of Japanese patients with exacerbations of chronic obstructive pulmonary disease
}

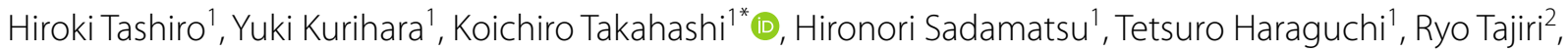
Ayako Takamori², Shinya Kimura ${ }^{1}$ and Naoko Sueoka-Aragane ${ }^{1}$

\begin{abstract}
Background: Exacerbations are critical events in chronic pulmonary obstructive disease (COPD). The frequency of COPD exacerbations is associated with the prognosis, including mortality, but no useful biomarker has been established.
\end{abstract}

Methods: The present retrospective study investigated 481 COPD patients. Clinical features in the stable period were compared between patients who experienced severe exacerbation $(n=88,18.3 \%)$ and those who never experienced severe exacerbation $(n=393,81.7 \%)$. In the patients who experienced exacerbations, clinical features were also compared between frequent exacerbators (exacerbation rate $\geq 2$ times/year, $n=27,30.7 \%$ ) and infrequent exacerbators (1 time/year, $n=61,69.3 \%)$.

Results: Compared to COPD patients who never experienced exacerbations, body mass index (BMI), serum albumin, and pulmonary functions were significantly lower, and the cardiovascular disease comorbidity rate, COPD assessment test score, modified Medical Research Council dyspnea scale, and use of long-term oxygen therapy, long-acting $\beta_{2}$ adrenergic agonist therapy, inhaled corticosteroid therapy, and macrolide therapy were significantly higher in COPD patients with exacerbations (all $p<0.01$ ). In patients who experienced exacerbations, frequent exacerbators had significantly lower \% forced expiratory volume in $1.0 \mathrm{~s}$ and a higher risk of critical exacerbations, percentage of blood eosinophils, history of mechanical ventilation use, and use of long-term oxygen therapy and of macrolide therapy than infrequent exacerbators (all $p<0.01$ ). On multivariate analysis, the percentage of blood eosinophils was the parameter most correlated with exacerbation frequency ( $\beta$ value [95\% confidence interval] 1.45 [1.12-1.88], $p<0.01$ ).

Conclusion: Blood eosinophil in the stable period is the factor most correlated with the frequency of severe exacerbations.

Trial registration: The patients in this study was registered retrospectively

Keywords: Exacerbation, Frequency, Blood eosinophil

\footnotetext{
*Correspondence: takahak@cc.saga-u.ac.jp

${ }^{1}$ Division of Hematology, Respiratory Medicine and Oncology,

Department of Internal Medicine, Faculty of Medicine, Saga University,

5-1-1 Nabeshima, Saga, Saga Prefecture 849-8501, Japan

Full list of author information is available at the end of the article
}

\begin{abstract}
Background
Chronic pulmonary obstructive disease (COPD) is a common respiratory disease, with a reported global prevalence of 251 million cases, and it is also an important life-threatening lung disease that is predicted to become the third leading cause of death worldwide by 2030 [1]. Exacerbation is one of the crucial events in patients with
\end{abstract}


COPD, triggered by respiratory infections with bacteria and viruses and other factors such as pollution $[2,3]$. It is also associated with worsening of mortality, lung function, and health-related quality of life. For example, a large real-world dataset of 177,207 patients with COPD in Japan showed that higher mortality is associated with pneumonia caused by microbes and aspiration pneumonia, which are causative factors for acute exacerbation of COPD [4]. Asian and Western studies also reported that exacerbation has a negative effect on COPD-associated quality of life (QOL), with decreased lung function [57]. The severity and frequency of exacerbations should be considered when attempting to predict the prognosis of COPD patients. In a prospective cohort of 304 men with COPD followed-up for 5 years, exacerbations requiring hospitalization showed an independent negative impact on patient prognosis [8]. Others have identified that moderate to severe exacerbation has a greater association with in-hospital death than mild exacerbation [9], and the 1-year mortality rate was also significantly higher for patients admitted to the intensive care unit for respiratory failure [10]. Additionally, frequent exacerbators showed a poor prognosis, with future frequent exacerbations identified as an independent risk factor in a 1-year prospective observational trial involving 90 Japanese patients with COPD [11]. To predict and prevent a worse clinical course in COPD patients, a more precise biomarker for frequent and severe exacerbations is necessary.

There is increasing evidence supporting the use of blood eosinophils as an accessible and beneficial biomarker for exacerbations in COPD patients. In particular, the percentage of blood eosinophils is considered a predictor of the effectiveness of inhaled corticosteroid (ICS) therapy to attenuate exacerbations $[12,13]$. In patients with a percentage of blood eosinophils $>2 \%$, ICS had a beneficial effect, reducing the exacerbation rate compared to those with a percentage of blood eosinophils $<2 \%$ [14]. Recently, the IMPACT study, which included moderate-to-very-severe COPD patients with at least one moderate or severe exacerbation in the previous year, also showed that ICS attenuated exacerbations for COPD patients with higher blood eosinophil counts [15]. Thus, the blood eosinophil has potential as a predictive biomarker of exacerbations in COPD patients, but it is still unclear how important it is for severe and frequent exacerbations in Japanese patients with COPD compared to other parameters such as airway obstruction, history of mechanical ventilation use, long-term oxygen therapy, and other treatments.

In this study, the initial focus was on characteristics of COPD patients, which were compared between patients who experienced severe exacerbations and those who never experienced severe exacerbations to clarify the factors related to severe exacerbations. Second, parameters associated with the frequency of severe exacerbations were identified, and multivariate analysis was performed to identify the parameters most related to exacerbation frequency. The percentage of blood eosinophils in the stable period was found to be the factor most correlated with the frequency of exacerbations, rather than FEV1.0\% predicted, history of mechanical ventilation use, and long-term oxygen therapy. These results will contribute to the practical prediction of the prognosis of COPD patients with frequent severe exacerbations and to the selection of treatment including ICS.

\section{Methods}

\section{Patients and setting}

A total of 729 patients with the International Classification of Diseases, 10th Revision, Clinical Modification [ICD-10-CM] code for COPD (J449) in their medical records at the Saga University Hospital between 2009 and 2019 were retrospectively reviewed. From among these patients, two expert pulmonary physicians extracted 481 patients with COPD, considering the following definition criteria referring to the previous reports [16-19]: (1) age $>40$ years; (2) forced expiratory volume in $1.0 \mathrm{~s}$ (FEV1.0)/forced vital capacity (FVC) ratio $<0.7$; (3) smoking index $>10$ pack-years; (4) persistent respiratory symptoms such as dyspnea, cough, and sputum; and (5) no medical history or current diagnosis of asthma. A severe exacerbation was defined as any sustained increase in respiratory symptoms compared with the stable phase and need for hospitalization considering symptoms, respiratory condition, and clinical findings with treatment of systemic corticosteroid or antibiotics, alone or combination. The need for hospitalization with an exacerbation was determined by the pulmonary physician. Causes of exacerbations were classified into 3 groups as bacterial infection, viral infection, and others, including unknown, considering respiratory sample cultures, examination of viral antigens for influenza, and radiological findings with physical findings. To standardize exacerbation frequency, the annual exacerbation rate was determined, and the maximum number of severe exacerbations per year from 2009 to 2019 was examined. Additionally, an infrequent exacerbator was defined as a patient whose maximum annual exacerbation rate was 1 /year, and a frequent exacerbator was defined as a patient whose maximum annual exacerbation rate was more than $2 /$ year. To assess the correlations between the maximum annual exacerbation rate and clinical factors, patients' characteristics, COPD assessment test (CAT) score, modified Medical Research Council (mMRC) dyspnea scale, laboratory data, pulmonary function test results, transtricuspid pressure 
gradient (TRPG) on echocardiography, and treatment regimens were evaluated in the stable phase which was defined as no use of oral corticosteroids or antibiotics, no unscheduled doctor's visit, or no hospitalization due to exacerbation of COPD in the past 4 weeks. Blood eosinophil was also evaluated in the stable phase according to the previous report [20]. For patients who never experienced exacerbations, the newest data in the medical record were evaluated. A critical exacerbation was defined as one with a fatal outcome. $\mathrm{CO}_{2}$ retention was defined as $\mathrm{CO}_{2}>45 \mathrm{mmHg}$ on arterial blood gas analysis. This study was approved by the ethics committee of Saga University Hospital (approval number: 2020-01-R04, approval date: Mar 30, 2020) and was performed in accordance with the 1964 Declaration of Helsinki.

\section{Comorbidities}

Hypertension, diabetes mellitus, hyperlipidemia and cardiovascular disease were diagnosed by the physicians. Cardiovascular disease included coronary artery disease, valvular disease, cardiac arrhythmias such as atrial fibrillation, and chronic heart failure diagnosed by echocardiography.

\section{Statistical analysis}

The clinical data were analyzed by Student's $t$-test for continuous variables or the chi-squared test for categorical variables. In patients who experienced exacerbations, univariate analysis was performed to extract significant variables in patients with infrequent exacerbations versus those with frequent exacerbations. To evaluate the most highly predictive variables in these 2 groups, multivariate analysis with logistic regression analysis was performed for categorical variables, and multiple linear regression analysis was performed for continuous variables. Quantitative data are presented as means \pm standard deviation (SD), and odds ratios or $\beta$ coefficient values were calculated. Statistical analysis was performed with JMP Pro version 14.2.0 software (SAS Institute Inc., Cary, NC, USA).

\section{Results \\ Clinical characteristics of COPD patients with and without severe exacerbations}

In the present study, 481 patients with COPD were analyzed. To examine the clinical impact of severe exacerbations, the 481 patients were divided into 393 patients who never experienced severe exacerbations and 88 patients who experienced severe exacerbations from 2009 to 2019. There were no significant differences in age, sex, height, and smoking history, but weight and the body mass index were significantly lower in patients with exacerbations than in those without exacerbations $(\mathrm{p}<0.01$, respectively). As comorbidities, hypertension, diabetes mellitus, and hyperlipidemia were not different in the 2 groups, but cardiovascular disease was significantly more common in patients with exacerbations than in those without exacerbations $(30.7 \%$ vs $15.4 \%$, $\mathrm{p}<0.01)$. The CAT score and the mMRC dyspnea scale were higher in patients with exacerbations than in those without exacerbations (both $\mathrm{p}<0.01$ ). Of the laboratory data, the white blood cell count and blood eosinophil were not different between the 2 groups, but serum albumin was significantly lower in patients with exacerbations than in those without exacerbations $(\mathrm{p}<0.01)$. On pulmonary function testing, VC, FVC, FEV 1.0, FEV1.0/ FVC, \%FEV1.0, and diffusing capacity of the lung for carbon monoxide (DLco) were significantly lower in patients with severe exacerbations than in those without severe exacerbations (all $\mathrm{p}<0.01$ ). TRPG, which is one of the predictors of pulmonary hypertension, was also higher in patients with exacerbations $(\mathrm{p}<0.01)$. As for treatment, long-term oxygen therapy, long acting $\beta_{2}$ adrenergic agonists (LABAs), ICS, and macrolides were used significantly more in patients with exacerbations than in those without exacerbations (all $\mathrm{p}<0.01$ ) (Table 1). These data showed that severe exacerbations were closely associated with the physical and clinical characteristics of patients with COPD.

\section{Evaluation of the frequency and causes of exacerbations in patients with COPD}

To clarify the impact of exacerbation frequency in patients with COPD, the analysis focused on the 88 patients who experienced exacerbations, and the annual exacerbation rate was extracted for the maximum number of severe exacerbations in 1 year from 2009 to 2019 . The 88 patients were divided into those whose annual exacerbation rate was once/year (infrequent exacerbators, 62 patients) and the 26 patients whose annual exacerbation rate was $\geq 2$ times/year (frequent exacerbators). The annual exacerbation rate of the frequent exacerbators was $2.6 \pm 0.3$ (range 2-8 times). The total number of exacerbations from 2009 to 2019 was 65 in infrequent exacerbators and 111 in frequent exacerbators. As the causes of the exacerbations, bacterial infection was the most common, and viral infection and others were uncommon in the present study (Table 2).

\section{Comparison of clinical characteristics in COPD patients with and without frequent exacerbations}

To address the clinical impact of exacerbation frequency, clinical characteristics were compared between infrequent exacerbators and frequent exacerbators. BMI was significantly lower in frequent exacerbators than in infrequent exacerbators $(\mathrm{p}=0.03)$. Critical exacerbations with 
Table 1 Clinical characteristics in COPD patients with severe exacerbation versus those without severe exacerbation

\begin{tabular}{|c|c|c|c|}
\hline & Non exacerbator & Exacerbator & $\mathrm{p}$ value \\
\hline n & 393 & 88 & \\
\hline Age (years) & $71.6 \pm 0.4$ & $73.3 \pm 1.0$ & 0.1 \\
\hline Gender (male/female) & $371 / 22$ & $83 / 5$ & 0.98 \\
\hline Height & $162.9 \pm 0.4$ & $162.1 \pm 0.8$ & 0.62 \\
\hline Body weight & $59.1 \pm 0.6$ & $53.5 \pm 1.1$ & $<0.01$ \\
\hline BMI $\left(\mathrm{kg} / \mathrm{m}^{2}\right)$ & $22.1 \pm 0.2$ & $20.3 \pm 0.4$ & $<0.01$ \\
\hline $\begin{array}{l}\text { Smoking history (pack- } \\
\text { year) }\end{array}$ & $58.9 \pm 1.6$ & $63.0 \pm 2.7$ & 0.29 \\
\hline \multicolumn{4}{|l|}{ Comorbidity } \\
\hline Hypertension & $185(47.1 \%)$ & $42(47.7 \%)$ & 0.91 \\
\hline Diabetes mellitus & 77 (19.7\%) & $18(20.5 \%)$ & 0.87 \\
\hline Hyperlipidemia & $60(15.4 \%)$ & $15(17.1 \%)$ & 0.69 \\
\hline Cardiovascular disease & $60(15.4 \%)$ & $27(30.7 \%)$ & $<0.01$ \\
\hline COPD assessment test & $10.3 \pm 0.5$ & $19.9 \pm 1.3$ & $<0.01$ \\
\hline $\begin{array}{l}\text { mMRC dyspnea scale, } \\
\text { grades }\end{array}$ & $1.48 \pm 0.12$ & $2.67 \pm 0.71$ & $<0.01$ \\
\hline \multicolumn{4}{|l|}{ Laboratory data } \\
\hline White blood cell (/ml) & $6652.4 \pm 82.4$ & $6830.7 \pm 194.6$ & 0.36 \\
\hline Blood eosinophil (\%) & $2.73 \pm 0.11$ & $2.84 \pm 0.27$ & 0.66 \\
\hline $\begin{array}{l}\text { Blood eosinophil count } \\
\text { (/ml) }\end{array}$ & $175.4 \pm 7.4$ & $184.2 \pm 17.4$ & 0.61 \\
\hline Serum albumin (g/dl) & $3.81 \pm 0.02$ & $3.60 \pm 0.06$ & $<0.01$ \\
\hline \multicolumn{4}{|l|}{ Pulmonary function test } \\
\hline $\mathrm{VC}(\mathrm{L})$ & $3.16 \pm 0.04$ & $2.84 \pm 0.09$ & $<0.01$ \\
\hline $\mathrm{FVC}(\mathrm{L})$ & $3.02 \pm 0.04$ & $2.65 \pm 0.09$ & $<0.01$ \\
\hline FEV1.0 (L) & $1.66 \pm 0.03$ & $1.24 \pm 0.06$ & $<0.01$ \\
\hline FEV1.0/FVC (\%) & $54.4 \pm 0.0$ & $46.6 \pm 0.0$ & $<0.01$ \\
\hline \%FEV1.0 (\%) & $75.4 \pm 1.1$ & $58.6 \pm 2.6$ & $<0.01$ \\
\hline DLco (\%) & $71.0 \pm 2.3$ & $55.7 \pm 3.7$ & $<0.01$ \\
\hline TRPG (mmHg) & $27 \pm 1.1$ & $38.5 \pm 2.2$ & $<0.01$ \\
\hline \multicolumn{4}{|l|}{ Treatment } \\
\hline $\begin{array}{l}\text { Long-term oxygen } \\
\text { therapy }\end{array}$ & $20(5.1 \%)$ & $42(47.7 \%)$ & $<0.01$ \\
\hline LAMA & $176(45.1 \%)$ & 49 (55.7\%) & 0.07 \\
\hline LABA & $155(39.7 \%)$ & $60(68.2 \%)$ & $<0.01$ \\
\hline ICS & $73(18.7 \%)$ & $41(46.6 \%)$ & $<0.01$ \\
\hline Macrolide & $27(7.0 \%)$ & $23(26.1 \%)$ & $<0.01$ \\
\hline$\beta$ blocker & 37 (9.5\%) & $12(13.6 \%)$ & 0.27 \\
\hline
\end{tabular}

COPD chronic obstructive pulmonary disease, $B M I$ body mass index, $m M R C$ modified medical research council, VC vital capacity, FVC forced vital capacity, FEV1.0 forced expiratory volume in $1.0 \mathrm{~s}$, DLco diffusing capacity of lung for carbon monoxide, TRPG transtricuspid pressure gradient, LAMA long acting muscarinic antagonist, $L A B A$ long acting $\beta_{2}$ adrenergic agonist, ICS inhaled corticosteroid. Data are presented as mean \pm standard deviation

fatal outcomes were significantly more common in frequent exacerbators $(\mathrm{p}<0.01)$. There were no differences in comorbidities and the CAT score in these 2 groups. As for the laboratory data, the percentage of blood
Table 2 Frequency and causes for exacerbation in patients with COPD

\begin{tabular}{lll}
\hline & $\begin{array}{l}\text { Infrequent } \\
\text { exacerbator }\end{array}$ & Frequent exacerbator \\
\hline $\mathrm{n}$ & 61 & 27 \\
Annual exacerbation rate & 1 & $2.6 \pm 0.3$ \\
$\begin{array}{l}\text { Total events of exacerbation } \\
\text { Causes of exacerbations }\end{array}$ & 65 & 111 \\
$\begin{array}{l}\text { Bacterial infection } \\
\text { Viral infection }\end{array}$ & $47(72.3 \%)$ & $91(82 \%)$ \\
Others include unknown & $3(4.6 \%)$ & $4(3.6 \%)$ \\
\hline
\end{tabular}

Data are presented as mean \pm standard deviation

eosinophils and the blood eosinophil count were significantly higher in frequent exacerbators than in infrequent exacerbators $(\mathrm{p}<0.01, \mathrm{p}=0.03$ respectively). The frequency of patients with $\mathrm{CO}_{2}$ retention $(>45 \mathrm{mmHg}$ ) on arterial blood gas analysis was higher in frequent exacerbators $(p=0.05)$. On pulmonary function test results, \%FEV1.0 was significantly lower in frequent exacerbators than in infrequent exacerbators $(\mathrm{p}<0.01)$. TRPG was not different between the 2 groups, and a history of mechanical ventilation use for exacerbations was significantly higher in frequent exacerbators $(\mathrm{p}<0.01)$. As for treatment, the frequencies of the use of long-term oxygen therapy, long-acting muscarinic antagonists (LAMAs), and macrolides was higher in frequent exacerbators than in infrequent exacerbators $(\mathrm{p}<0.01, \mathrm{p}=0.02$, $\mathrm{p}<0.01$ respectively), but the use of ICS was not different between the 2 groups (Table 3). We also compared clinical characteristics between COPD patients with frequent exacerbations and those without exacerbations. BMI and pulmonary function testing including $\mathrm{VC}, \mathrm{FVC}$, FEV 1.0, FEV1.0/FVC, \%FEV1.0 are significantly lower (all $\mathrm{p}<0.01$ ) and CAT score, blood eosinophil, TRPG are significantly higher in patients with frequent exacerbations than in those without exacerbations $(\mathrm{p}<0.01, \mathrm{p}=0.02$, $\mathrm{p}<0.01$ respectively). As for treatment, long-term oxygen therapy, LAMA, LABA, ICS, and macrolides were used significantly more in patients with frequent exacerbations than in those without exacerbations (all $\mathrm{p}<0.01$ ) (Additional file 1: Table E1).

Multivariate analysis and correlation analysis of the clinical characteristics in COPD patients with frequent exacerbations versus those with infrequent exacerbations To evaluate the most useful predictor of the frequency of exacerbations in COPD patients, multivariate analysis was performed using variables that were significant in frequent exacerbators compared to infrequent exacerbators, such as the rate of critical exacerbations, 
Table 3 Comparison of clinical characteristics in COPD patients with frequent exacerbation versus those with infrequent exacerbation

\begin{tabular}{|c|c|c|c|}
\hline & Infrequent exacerbator & Frequent exacerbator & $\begin{array}{l}\text { Univariate } \\
\text { analysis }\end{array}$ \\
\hline$n$ & 61 & 27 & \\
\hline Age (years) & $74.0 \pm 1.2$ & $71.7 \pm 0.4$ & 0.3 \\
\hline $\mathrm{BMI}\left(\mathrm{kg} / \mathrm{m}^{2}\right)$ & $20.9 \pm 0.4$ & $19.0 \pm 0.8$ & 0.03 \\
\hline Smoking history (pack-year) & $61.2 \pm 4.4$ & $67.3 \pm 7.5$ & 0.46 \\
\hline \multicolumn{4}{|l|}{ Comorbidity } \\
\hline Hypertension & $30(49.2 \%)$ & $12(44.4 \%)$ & 0.68 \\
\hline Diabetes mellitus & $10(16.4 \%)$ & $8(29.6 \%)$ & 0.17 \\
\hline Hyperlipidemia & $12(19.7 \%)$ & $3(11.1 \%)$ & 0.31 \\
\hline Cardiovascular disease & $19(31.2 \%)$ & $8(30.7 \%)$ & 0.89 \\
\hline COPD assessment test & $19.8 \pm 2.1$ & $20.0 \pm 1.7$ & 0.94 \\
\hline Critical exacerbation & $4(6.6 \%)$ & $10(38.5 \%)$ & $<0.01$ \\
\hline \multicolumn{4}{|l|}{ Laboratory data } \\
\hline White blood cell (/ml) & $7067.2 \pm 217.8$ & $6296.3 \pm 387.1$ & 0.07 \\
\hline Blood eosinophil (\%) & $2.44 \pm 0.29$ & $3.76 \pm 0.55$ & $<0.01$ \\
\hline Blood eosinophil count (/ml) & $154.7 \pm 16.9$ & $233.4 \pm 37.4$ & 0.03 \\
\hline Serum albumin $(\mathrm{g} / \mathrm{dl})$ & $3.60 \pm 0.07$ & $3.62 \pm 0.09$ & 0.84 \\
\hline $\mathrm{CO}_{2}$ retention & $12 / 60(20 \%)$ & $11 / 27(40.7 \%)$ & 0.05 \\
\hline \multicolumn{4}{|l|}{ Pulmonary function test } \\
\hline $\mathrm{VC}(\mathrm{L})$ & $2.89 \pm 0.11$ & $2.73 \pm 0.14$ & 0.42 \\
\hline FVC $(\mathrm{L})$ & $2.70 \pm 0.11$ & $2.52 \pm 0.13$ & 0.35 \\
\hline FEV1.0 (L) & $1.32 \pm 0.08$ & $1.05 \pm 0.09$ & 0.04 \\
\hline FEV1.0/FVC (\%) & $48.6 \pm 1.8$ & $42.2 \pm 2.6$ & 0.05 \\
\hline \%FEV1.0 (\%) & $63.3 \pm 3.3$ & $48.0 \pm 3.5$ & $<0.01$ \\
\hline DLco (\%) & $54.4 \pm 4.6$ & $59.3 \pm 6.3$ & 0.56 \\
\hline TRPG (mmHg) & $36.2 \pm 2.4$ & $42.6 \pm 4.5$ & 0.18 \\
\hline \multicolumn{4}{|l|}{ History } \\
\hline Mechanical ventilation use & $7(11.5 \%)$ & $11(40.7 \%)$ & $<0.01$ \\
\hline \multicolumn{4}{|l|}{ Treatment } \\
\hline Long-term oxygen therapy & $21(34.4 \%)$ & $21(77.8 \%)$ & $<0.01$ \\
\hline Home ventilation use & $4(6.6 \%)$ & $4(14.8 \%)$ & 0.23 \\
\hline LAMA & $29(47.5 \%)$ & $20(74.1 \%)$ & 0.02 \\
\hline$\angle A B A$ & $38(62.3 \%)$ & $22(81.5 \%)$ & 0.07 \\
\hline ICS & $29(47.5 \%)$ & $12(44.4 \%)$ & 0.79 \\
\hline Macrolide & $10(16.4 \%)$ & $13(48.1 \%)$ & $<0.01$ \\
\hline$\beta$ blocker & $8(13.1 \%)$ & $4(14.8 \%)$ & 0.8 \\
\hline
\end{tabular}

COPD chronic obstructive pulmonary disease, BMI body mass index, VC vital capacity, FVC forced vital capacity, FEV1.0 forced expiratory volume in $1.0 \mathrm{~s}$, DLCo diffusing capacity of lung for carbon monoxide, TRPG transtricuspid pressure gradient, LAMA long acting muscarinic antagonist, LABA long acting $\beta_{2}$ adrenergic agonist, ICS inhaled corticosteroid. Data are presented as mean \pm standard deviation

percentage of blood eosinophils, \%FEV1.0, history of mechanical ventilation use, long-term oxygen therapy, macrolide use, $\mathrm{BMI}$ and rate of $\mathrm{CO}_{2}$ retentions on univariate analysis. Critical exacerbation (odds ratio or $\beta$ value [95\% confidence interval] 6.07 [1.06-36.67], $\mathrm{p}=0.04)$ and mechanical ventilation use (5.49 [1.1925.19], $\mathrm{p}=0.03$ ) were significant as independent predictors, and the percentage of blood eosinophils was the most significant of these variables (1.45 [1.12-1.88], $\mathrm{p}<0.01$ ) (Table 4). We also performed multivariate analysis using variables that were significant in patient with frequent exacerbations and in those without exacerbation. Long-term oxygen therapy (37.09 [3.95-348], $\mathrm{p}<0.01)$ and the percentage of blood eosinophil $(1.64$ $[1.12-2.64], \mathrm{p}=0.02)$ were significant as independent predictors (Additional file 1: Table E2). 
Table 4 Multivariate analysis of the clinical characteristics in COPD patients with frequent exacerbation versus those with infrequent exacerbation

\begin{tabular}{lllr}
\hline & \multicolumn{2}{l}{ Multivariate analysis } \\
\cline { 2 - 4 } & $\begin{array}{l}\text { Adjusted } \\
\text { OR or } \boldsymbol{\beta}\end{array}$ & $\mathbf{9 5 \%} \mathbf{C l}$ & p value \\
\hline Critical exacerbation & 6.07 & $1.06-34.67$ & 0.04 \\
Blood eosinophil (\%) & 1.45 & $1.12-1.88$ & $<0.01$ \\
\%FEV1.0 (\%) & 0.3 & $0.01-7.01$ & 0.46 \\
Mechanical ventilation use & 5.49 & $1.19-25.19$ & 0.03 \\
Long-term oxygen therapy & 1.69 & $0.41-6.96$ & 0.47 \\
Macrolide & 2.28 & $0.59-8.82$ & 0.23 \\
BMI & 0.91 & $0.75-1.12$ & 0.38 \\
CO $_{2}$ retention & 1.16 & $0.23-5.83$ & 0.85 \\
\hline
\end{tabular}

OR odds ratio, $\beta$ standardized $\beta$ value, $C l$ confidence interval, $B M I$ body mass index

\section{Discussion}

In the present real-world study, BMI, serum albumin, and pulmonary functions including VC, FVC, FEV1.0, FEV1.0/FVC, \%FEV1.0, and DLco were significantly lower, and the cardiovascular disease comorbidity rate, COPD assessment test score, mMRC dyspnea scale, and use of long-term oxygen therapy, LABAs, ICS, and macrolides were significantly higher in COPD patients who experienced exacerbations than in COPD patients who never experienced severe exacerbations. Of patients who experienced exacerbations, frequent exacerbators had significantly lower BMI, FEV1.0, and \%FEV1.0, and higher risk of critical exacerbations, blood eosinophils, history of mechanical ventilation use, use of long-term oxygen therapy, LAMAs, and macrolides than infrequent exacerbators. Multivariate analysis showed that the parameter most correlated with exacerbation frequency was the percentage of blood eosinophils.

Exacerbation is one of the independent phenotypes in COPD patients who develop worse health conditions, including symptoms and pulmonary function, which is supported by many previous reports [21, 22]. For example, there was an $8 \%$ increase in the risk of exacerbations per unit increase in CAT [23], and additional exacerbation was associated with a greater decline of $6-7 \mathrm{ml}$ in FEV1.0 in a huge cohort study $[24,25]$, consistent with the results of the current study (Table 1). As for comorbidities, cardiovascular diseases were more common in patients who had exacerbations with significantly higher pulmonary artery pressure (Table 1). Cardiovascular events are common in COPD patients, and $20.5 \%$ of stable COPD patients had unrecognized heart failure [26, 27]; they were also significantly associated with longterm mortality in COPD patients with exacerbations [28].
Exacerbation frequency is also an important factor related to the prognosis of COPD patients. Donaldson et al. analyzed 109 patients with COPD who experienced 757 exacerbations and suggested that FEV1.0 was decreased at $40.1 \mathrm{ml} /$ year in frequent exacerbators compared to $32.1 \mathrm{ml} /$ year in infrequent exacerbators [25]. In a 1-year prospective observational trial of Japanese COPD patients, Tomioka et al. reported that frequent exacerbators had lower BMIs and higher CAT scores than infrequent exacerbators [11]. Moreover, the retrospective UPLIFT study of 6000 patients with COPD and the 3-year observational ECLIPS study of 2000 patients with COPD reported that the patients with higher exacerbation rates had more rapid lung function decline [29, 30]. Interestingly, more than $20 \%$ of COPD patients with GOLD stage $2(50 \%<$ FEV $1.0<80 \%$ predicted $)$ had two or more annual exacerbations, and the frequency in the previous year predicted the future frequency [30]. These data suggest that frequency is also an independent phenotype of COPD patients with exacerbation.

The present results suggest that the percentage of blood eosinophils in the stable period is the factor most correlated with exacerbation frequency compared to other variables, including the critical exacerbation rate, $\%$ FEV1.0, history of mechanical ventilation use, use of long-term oxygen therapy, use of macrolides, BMI and $\mathrm{CO}_{2}$ retention rate (Table 4). A previous paper reported that COPD patients with a blood eosinophil count $>500$ cells/ $\mu \mathrm{l}$ had a 1.43 times higher risk of exacerbation in a huge database analysis [31], and others reported that patients with a blood eosinophil count $>340$ cells $/ \mu$ lalso had a 1.76-fold increased risk of severe exacerbation [32], which is consistent with the present result. Notably, the blood eosinophil was not significantly different between COPD patients who experienced exacerbations and those who never experienced exacerbations in the present study, which supported the association of blood eosinophils with exacerbation frequency, but not exacerbation itself (Table 1).

To decrease frequent exacerbations, ICS treatment was considered for suppression of airway inflammation. Recently, two randomized trials showed that ICS therapy suppressed moderate to severe exacerbations in COPD patients with improvement of pulmonary function [33, 34]. In that study, the COPD patients with blood eosinophil counts $\geq 310$ cells $/ \mu$ l showed a greater reduction of the exacerbation rate with improvement of FEV1.0, symptoms, and QOL score than those with blood eosinophil counts $<90$ cells $/ \mu l$ [15]. Importantly, the present results showed that the rate of patients treated by ICS was no different between frequent exacerbators and infrequent exacerbators (Table 3), which might contribute to the current prognostic results. 
There are several limitations in this study. First, it was not possible to completely exclude patients with asthma-COPD overlap from the current study population. Because such patients had frequent exacerbations with higher blood eosinophil levels, the current results in frequent exacerbators might be affected by this population. Second, unreported exacerbations were also reported to be important for health status, as much as reported exacerbations, in COPD patients [35]. The effect of unreported exacerbations, which might have impacted the current results, was not evaluated. Third, the disease duration of COPD might be different between COPD patients with exacerbations and those without exacerbations which might influence of the present results. Fourth, decision of hospitalization for definition of severe exacerbation is depending on physician's judgment which might also involve the present results. Finally, the present study involved patients at a single hospital with limited ethnic diversity and small sample size. To confirm the validity of the present results, multicenter prospective studies with a larger number of patients should be performed.

\section{Conclusions}

The percentage of blood eosinophils in the stable period was the factor most correlated with the frequency of severe exacerbations, rather than FEV1.0\%predicted, history of mechanical ventilation use, and long-term oxygen therapy. These results will contribute to predicting the prognosis of COPD patients and the selection of treatment including ICS.

\section{Supplementary information}

Supplementary information accompanies this paper at https://doi. org/10.1186/s12890-020-01362-w.

Additional file 1. Table E1. Comparison of clinical characteristics in COPD patients with frequent exacerbation vs those without exacerbation. Table E2. Multivariate analysis of the clinical characteristics in COPD patients with frequent exacerbation vs those without exacerbation.

\section{Abbreviations \\ COPD: Chronic pulmonary obstructive disease; BMI: Body mass index; QOL: Quality of life; ICS: Inhaled corticosteroid; FEV1.0: Forced expiratory volume in $1.0 \mathrm{~s}$; FVC: Forced vital capacity; CAT: COPD assessment test; mMRC: Modified Medical Research Council; TRPG: Transtricuspid pressure gradient; SD: Standard deviation; DLCo: Diffusing capacity of the lung for carbon monoxide; LABAs: Long acting $\beta_{2}$ adrenergic agonists; LAMAs: Long-acting muscarinic antago- nists; OR: Odds ratio; $\beta$ : Standardized $\beta$ value; $\mathrm{Cl}$ : Confidence interval.}

\section{Acknowledgements}

Not applicable.

\section{Authors' contributions}

HT, YK and KT conceived and designed the project. HT, YK, HS and TH analyzed clinical data. RT and AT advised for statistical analysis. HT, YK, KT and NA prepared the manuscript with input from all other authors. KT, SK and NA performed final check of manuscript. All authors have read and approved the manuscript.

\section{Funding}

This research did not receive any specific grant from funding agencies in the public, commercial, or not-for-profit sectors.

\section{Availability of data and materials}

The datasets used and analyzed during the current study are available from the corresponding author on reasonable request.

\section{Ethics approval and consent to participate}

This study was approved by the ethics committee of Saga University Hospital (Approval Number: 2020-01-R-04, Approval Date: Mar 30, 2020) and was performed in accordance with the 1964 Declaration of Helsinki. The ethics committee allowed us to administrate all of the raw data from medical record in specific off-line computer. HT as the research conductor got permission in the ethics approval. Informed consent was obtained in the form of opt-out on the web-site. Those who rejected were excluded.

\section{Consent for publication}

Not applicable.

\section{Competing interests}

The authors declare that they have no competing interests.

\section{Author details}

${ }^{1}$ Division of Hematology, Respiratory Medicine and Oncology, Department of Internal Medicine, Faculty of Medicine, Saga University, 5-1-1 Nabeshima, Saga, Saga Prefecture 849-8501, Japan. ${ }^{2}$ Clinical Research Center, Saga University Hospital, Saga, Japan.

Received: 8 June 2020 Accepted: 26 November 2020

Published online: 07 December 2020

\section{References}

1. Halpin DMG, Celli BR, Criner GJ, Frith P, Lopez Varela MV, Salvi S, et al. The GOLD Summit on chronic obstructive pulmonary disease in low- and middle-income countries. Int J Tuberc Lung Dis. 2019;23(11):1131-41.

2. Soler N, Torres A, Ewig S, Gonzalez J, Celis R, El-Ebiary M, et al. Bronchial microbial patterns in severe exacerbations of chronic obstructive pulmonary disease (COPD) requiring mechanical ventilation. Am J Respir Crit Care Med. 1998;157(5 Pt 1):1498-505.

3. Viegi G, Maio S, Pistelli F, Baldacci S, Carrozzi L. Epidemiology of chronic obstructive pulmonary disease: health effects of air pollution. Respirology. 2006;11(5):523-32.

4. Hasegawa W, Yamauchi Y, Yasunaga H, Sunohara M, Jo T, Matsui H, et al. Factors affecting mortality following emergency admission for chronic obstructive pulmonary disease. BMC Pulm Med. 2014;14:151.

5. Suzuki M, Makita H, Ito YM, Nagai K, Konno S, Nishimura M, et al. Clinical features and determinants of COPD exacerbation in the Hokkaido COPD cohort study. Eur Respir J. 2014;43(5):1289-97.

6. Spencer S, Calverley PM, Burge PS, Jones PW. Impact of preventing exacerbations on deterioration of health status in COPD. Eur Respir J. 2004:23(5):698-702.

7. Seemungal TA, Donaldson GC, Paul EA, Bestall JC, Jeffries DJ, Wedzicha JA. Effect of exacerbation on quality of life in patients with chronic obstructive pulmonary disease. Am J Respir Crit Care Med. 1998;157(5 Pt 1):1418-22.

8. Soler-Cataluna JJ, Martinez-Garcia MA, Roman Sanchez P, Salcedo E, Navarro M, Ochando R. Severe acute exacerbations and mortality in patients with chronic obstructive pulmonary disease. Thorax. 2005;60(11):925-31.

9. Bustamante-Fermosel A, De Miguel-Yanes JM, Duffort-Falco M, Munoz J. Mortality-related factors after hospitalization for acute exacerbation of chronic obstructive pulmonary disease: the burden of clinical features. Am J Emerg Med. 2007;25(5):515-22. 
10. Groenewegen KH, Schols AM, Wouters EF. Mortality and mortality-related factors after hospitalization for acute exacerbation of COPD. Chest. 2003;124(2):459-67.

11. Tomioka R, Kawayama T, Suetomo M, Kinoshita T, Tokunaga Y, Imaoka H, et al. "Frequent exacerbator" is a phenotype of poor prognosis in Japanese patients with chronic obstructive pulmonary disease. Int J Chron Obstruct Pulmon Dis. 2016;11:207-16.

12. Brusselle G, Pavord ID, Landis S, Pascoe S, Lettis S, Morjaria N, et al. Blood eosinophil levels as a biomarker in COPD. Respir Med. 2018:138:21-31.

13. Bafadhel M, Pavord ID, Russell REK. Eosinophils in COPD: just another biomarker? Lancet Respir Med. 2017;5(9):747-59.

14. Pavord ID, Lettis S, Locantore N, Pascoe S, Jones PW, Wedzicha JA, et al. Blood eosinophils and inhaled corticosteroid/long-acting beta-2 agonist efficacy in COPD. Thorax. 2016;71(2):118-25.

15. Pascoe S, Barnes N, Brusselle G, Compton C, Criner GJ, Dransfield MT, et al. Blood eosinophils and treatment response with triple and dual combination therapy in chronic obstructive pulmonary disease: analysis of the IMPACT trial. Lancet Respir Med. 2019;7(9):745-56.

16. Vogelmeier CF, Criner GJ, Martinez FJ, Anzueto A, Barnes PJ, Bourbeau J, et al. Global strategy for the diagnosis, management, and prevention of chronic obstructive lung disease 2017 Report. GOLD executive summary. Am J Respir Crit Care Med. 2017;195(5):557-82.

17. Choi HS, Rhee CK, Park YB, Yoo KH, Lim SY. Metabolic syndrome in early chronic obstructive pulmonary disease: gender differences and impact on exacerbation and medical costs. Int J Chron Obstruct Pulmon Dis. 2019;14:2873-83.

18. Mokari-Yamchi A, Jabbari M, Sharifi A, Barati M, Kheirouri S. Low FEV1 is associated with increased risk of cachexia In COPD patients. Int J Chron Obstruct Pulmon Dis. 2019;14:2433-40.

19. Mokari-Yamchi A, Sharifi A, Kheirouri S. Increased serum levels of S100A1, ZAG, and adiponectin in cachectic patients with COPD. Int J Chron Obstruct Pulmon Dis. 2018;13:3157-63.

20. Negewo NA, McDonald VM, Baines KJ, Wark PA, Simpson JL, Jones PW, et al. Peripheral blood eosinophils: a surrogate marker for airway eosinophilia in stable COPD. Int J Chron Obstruct Pulmon Dis. 2016;11:1495-504.

21. Lareau S, Moseson E, Slatore CG. Exacerbation of COPD. Am J Respir Crit Care Med. 2018;198(11):P21-2.

22. Hillas G, Perlikos F, Tzanakis N. Acute exacerbation of COPD: is it the "stroke of the lungs"? Int J Chron Obstruct Pulmon Dis. 2016;11:1579-86.

23. Rassouli F, Baty F, Stolz D, Albrich WC, Tamm M, Widmer S, et al. Longitudinal change of COPD assessment test (CAT) in a telehealthcare cohort is associated with exacerbation risk. Int J Chron Obstruct Pulmon Dis. 2017;12:3103-9.

24. Kanner RE, Anthonisen NR, Connett JE. Lower respiratory illnesses promote FEV(1) decline in current smokers but not ex-smokers with mild chronic obstructive pulmonary disease: results from the lung health study. Am J Respir Crit Care Med. 2001;164(3):358-64.

25. Donaldson GC, Seemungal TA, Bhowmik A, Wedzicha JA. Relationship between exacerbation frequency and lung function decline in chronic obstructive pulmonary disease. Thorax. 2002:57(10):847-52.

26. Johnston AK, Mannino DM, Hagan GW, Davis KJ, Kiri VA. Relationship between lung function impairment and incidence or recurrence of cardiovascular events in a middle-aged cohort. Thorax. 2008;63(7):599-605.

27. Rutten FH, Cramer MJ, Grobbee DE, Sachs AP, Kirkels JH, Lammers JW, et al. Unrecognized heart failure in elderly patients with stable chronic obstructive pulmonary disease. Eur Heart J. 2005;26(18):1887-94.

28. Singanayagam A, Schembri S, Chalmers JD. Predictors of mortality in hospitalized adults with acute exacerbation of chronic obstructive pulmonary disease. Ann Am Thorac Soc. 2013;10(2):81-9.

29. Halpin DM, Decramer M, Celli B, Kesten S, Liu D, Tashkin DP. Exacerbation frequency and course of COPD. Int J Chron Obstruct Pulmon Dis. 2012;7:653-61.

30. Hurst JR, Vestbo J, Anzueto A, Locantore N, Mullerova H, Tal-Singer R, et al. Susceptibility to exacerbation in chronic obstructive pulmonary disease. N Engl J Med. 2010:363(12):1128-38.

31. Kerkhof M, Freeman D, Jones R, Chisholm A, Price DB, Respiratory EG. Predicting frequent COPD exacerbations using primary care data. Int J Chron Obstruct Pulmon Dis. 2015;10:2439-50.

32. Vedel-Krogh S, Nielsen SF, Lange P, Vestbo J, Nordestgaard BG. Blood eosinophils and exacerbations in chronic obstructive pulmonary disease. The Copenhagen General Population Study. Am J Respir Crit Care Med. 2016:193(9):965-74

33. Lipson DA, Barnhart F, Brealey N, Brooks J, Criner GJ, Day NC, et al. Oncedaily single-inhaler triple versus dual therapy in patients with COPD. N Engl J Med. 2018;378(18):1671-80.

34. Ferguson GT, Rabe KF, Martinez FJ, Fabbri LM, Wang C, Ichinose M, et al. Triple therapy with budesonide/glycopyrrolate/formoterol fumarate with co-suspension delivery technology versus dual therapies in chronic obstructive pulmonary disease (KRONOS): a double-blind, parallel-group, multicentre, phase 3 randomised controlled trial. Lancet Respir Med. 2018;6(10):747-58

35. Langsetmo L, Platt RW, Ernst P, Bourbeau J. Underreporting exacerbation of chronic obstructive pulmonary disease in a longitudinal cohort. Am J Respir Crit Care Med. 2008;177(4):396-401.

\section{Publisher's Note}

Springer Nature remains neutral with regard to jurisdictional claims in published maps and institutional affiliations.
Ready to submit your research? Choose BMC and benefit from:

- fast, convenient online submission

- thorough peer review by experienced researchers in your field

- rapid publication on acceptance

- support for research data, including large and complex data types

- gold Open Access which fosters wider collaboration and increased citations

- maximum visibility for your research: over $100 \mathrm{M}$ website views per year

At BMC, research is always in progress.

Learn more biomedcentral.com/submissions 